ISSN: 2638-9231

\title{
Research
}

\section{Annals of Behavioral Neuroscience}

\section{Parent-Teacher Concordance for DSM V Diagnosis of Attention-Deficit/Hyperactivity Disorder in a Community Based Sample in Nigeria}

\author{
Oke OJ", Oseni SB, Adejuyigbe EA and Mosaku SK \\ Department of Paediatrics and Child Health, Obafemi Awolowo University, Ile Ife, Nigeria
}

*Correspondence: Oluwasola Julius Oke, Department of Paediatrics and Child Health, Obafemi Awolowo University, Ile Ife, Nigeria, E-mail: oketimilehin@gmail.com

Received: June 26, 2018; Accepted: October 29, 2018; Published: November 03, 2018

\begin{abstract}
Objective: To examine concordance between parent and teacher DBDRS in diagnosing ADHD among pupils in lle Ife, Nigeria.

Method: This study was carried out among 1385 children aged 5-12 years. Parents and teachers of the pupils were asked to complete the DBDRS checklist and children diagnosed for ADHD and their parents were interviewed for the symptoms and impaired function. Parent-teacher concordance of ADHD symptoms was evaluated.

Results: Agreement between parents and teachers DBDRS was found to be good for ADHD diagnosis and its subtypes $(r=0.525, p<0.001)$. There was a statistically significant positive correlation between parents' and teachers' DBDRS in ADHD diagnosis: Inattention, $r=0.522, p<0.001$, hyperactivity, $r=0.572, p<0.001$, Combined, $r=0.569, p<0.001$.

Conclusions: The good parent-teacher agreement implies that ADHD symptoms were noted appreciably by both parents and teachers in different settings with little bias.
\end{abstract}

Keywords: Informant, Concordance, ADHD, DBDRS

\section{Introduction}

Attention Deficit Hyperactivity Disorder (ADHD) is the commonest childhood neurobehavioural disorder characterized by symptoms of inattention, hyperactivity, and impulsiveness which must have been present before 12 years and persistent for at least 6 months occurring in two or more settings, such as school, home and causing significant impairment with cause of the symptoms excluding other mental disorder [1]. Presentations of ADHD can be informed of inattentive presentation, hyperactive/impulsive presentation, and a combined presentation [1]. It is a disorder that affects $1-20 \%$ of school-aged children and $60-80 \%$ of children symptoms or associated problems persist into adolescence [2-5]. Moreover, ADHD is frequently comorbid with disorders such as Oppositional Defiant Disorder (ODD), Conduct Disorder $(C D)$, learning disability and low self-esteem $[3,6]$. There are a variety of well-established behaviour rating scales that have obtained good results in discriminating between children with ADHD and control subjects. These scales include, Conner Rating Scale, Pelham Checklist, and Disruptive Behaviour Disorder rating scale (DBDRS) [714]. Other broadband checklists, such as the Achenbach Child Behaviour Checklist (CBCL), are useful, particularly in instances where the child may be experiencing cooccurring problems in other areas such as, anxiety, depression, and conduct problems [12-20]. ADHD rating scales are commonly used in the assessment of ADHD and are particularly useful to obtain information from different informants who observe the child in different settings [15-21]. Pelham et al. was first to use Disruptive 
Behavioural Disorder Rating Scale (DBDRS) to diagnosed ADHD [21]. The DBDRS had also been used by several other researchers to diagnosed ADHD: Meyer in South Africa used it to evaluate ADHD among North Sotho speaking primary school children in South Africa [22], Kashala et al. in Congo also diagnose ADHD with DBDRS among school children in Kinshasa, Democratic Republic of Congo [23], and Ambuabunos EA et al. in Nigeria made use of DBDRS in Community survey of attention-deficit/ hyperactivity disorder among primary school pupils in Benin City, Nigeria [24]. The DBDRS checklist evaluate ADHD symptoms according to DSM $V$ and has 45 items each describing the symptoms of $A D H D$, conduct disorder (CD) and Oppositional defiant disorder (ODD) to be rated by teachers or/and parent on a 4-point Likert scale according to the behavior of the child over previous 6 months. Eighteen (18 items) of the questions are for ADHD (9 items for hyperactivity, 6 items for inattention, 3 items for impulsiveness) and other items for conduct disorder (CD) and Oppositional defiant disorder(ODD).

To establish the diagnosis of ADHD, the Diagnostic and Statistical Manual of Mental Disorders [1] requires evidence of symptoms in more than one setting. Appropriate diagnosis of ADHD involve gathering information from various sources such as parent interviews, teacher interviews, direct observations, rating scales, psycho-educational assessments, record review, and medical evaluations [25-31]. Parent and teacher interviews are crucial methods used in the diagnostic process [25-31]. While parents spend major part of their time at home with the child and know him or her best, the information gathered from parents need to be considered with caution as parents may be biased about reporting their child's behavior [32-37]. However, teachers reports, can better determine how the child is performing in school compared to his or her age peers, as well as how the child's behaviour affects his or her ability to learn [38-42], Children may not be able to provide reliable and valid information about self and often bias in their self-report hence information about the behavior of the child in different settings is therefore needed to be obtained from parents and teachers to assess ADHD [43-50].

Biederman et al. [39] found that agreement between teachers and parents on items reflecting ADHD symptoms, measured by questions derived from the Diagnostic Interview for Children and Adolescents (DICA) to be low. Mitsis et al. [33] investigated parent and teacher agreement on DSM-IV ADHD criteria in a clinically referred sample and found correlations of inattention 0.39 for hyperactivity/impulsivity and 0.42 for the combined type. Wolraich et al. [34] found low agreement between Parent and teacher reports among 1573 children with a high risk for ADHD. Agreement regarding subtypes was even lower. A meta-analysis of ratings by different informants of children's behavioral and emotional by Antrop et al. revealed low levels of agreement for type, frequency, and severity of the problems [35]. Cohen and colleagues compared parent and teacher ratings on the Conners Rating scales and found moderate agreement [15]. ADHD diagnosis requires evidence of symptoms in more than one setting [51,52]. Studies done so far in Nigeria and Africa on ADHD had not analyzed the agreement between parents' and teachers in diagnosing ADHD. Therefore, agreement between parents and teachers DBDRS reports in diagnosing ADHD at home and school respectively were analyzed in this study.

\section{Materials and Methods Participants and sampling procedures}

This cross-sectional study was conducted among pupils aged 5-12 years in Ife Central LGA, Ile Ife, Nigeria. There are 41,778 children between 5-12 years of age in the LGA out of which 21,907 are males and 19,871 are female children [53]. The age group 5-12 years was chosen because the age group is recommended by American Psychiatry Association for ADHD diagnosis. These pupils were selected using the multistage random sampling technique. The sample was taken randomly from 18 public primary schools in Ife Central Local Government Area. The researchers contacted Educational Authorities in order to get the permission to approach the schools' headmistress/headmaster and to brief them about the aim of the study. With the authorization from school head in every school, a class from primary 1-6 was randomly selected and pupils were randomly identified by a table of random numbers. This process was necessary to ensure an equal distribution of participants according to their age and gender ( $a$ total of 1385 pupils). We subsequently sent letter to the parents of each selected child explaining the purpose of the research, a consent form, and DBDRS questionnaires to fill in at home. The teachers of the selected children were also asked to complete a consent form and to fill in the corresponding DBDRS questionnaires. A total of 1385 of the 1390 questionnaires that were distributed to the teachers and parents (response rate of 99.64\%) were returned completed and were included in the study. Children diagnosed for ADHD and their parents were also interviewed for the ADHD symptoms and impaired 
function. Therefore, data was collected from the parents and teachers of 1385 out of the 1390 schoolchildren that were initially selected (attrition: 10\%). There were boys 687 and 698 girls, aged between 5 and 12 years old. The $2^{\text {nd }}$ and $3^{\text {rd }}$ terms were chosen to ensure that the teachers had spent enough time with the pupils to attest to their individual behaviour.

\section{Sampling method}

A multistage random sampling technique was employed to select the subjects for this study. One of the two Local Governments was selected in lle-Ife by using simple random sampling method by balloting. Twenty five percent ( 18 schools) of the 72 schools in the selected Local Government Area were selected using simple random sampling method by balloting. Proportional probability sampling method was used to select 1385 children from the 18 selected schools. The number of pupils that were selected from each school was determined by sampling based on proportion to size of each selected school in relation to the total school enrolment for the 18 selected schools. Having identified the proportion of pupils for each school, simple random sampling was used for the selection of pupils in each selected school using a table of random numbers. The pupils in the selected schools were numbered according to the school register. There are six class levels in the schools (primaries 1-6). To ensure adequate representation of the various cohorts, the sample size of 1385 pupils was divided among classes 1-6.

\section{The instruments and study procedure}

Parents and teachers of the pupils were made to respond to checklist of ADHD on Disruptive Behavioural Disorder Rating Scale. The children were recruited from primary in lle Ife, Nigeria.

The Disruptive Behaviour Disorder Rating Scale (DBDRS): The Teachers 'and parents 'version of DBDRS described by Pelham and co-workers were used to screen pupils for ADHD symptoms according to DSM V (Appendix I, II). Parent version of the DBDRS was back translated to Yoruba (Appendix III). Scoring instruction for the DBDRS was used to interpret the information on the Disruptive Behaviour Disorder Rating Scale (Appendix IV). Information from parents was collected by researchers through the questionnaires. Prior to the interview, parents of each selected child were officially contacted through the head master/mistress of the school to inform them of the interviewer's visit and to request their consent to participate. When an agreement was met, all parents were visited at home. Information was obtained from the parents in English or Yoruba language as preferred by the parents. The teachers of selected children were also asked to complete the teachers' DBDRS questionnaire (Appendix I) for each participating child after they have been trained for one week with the particular questionnaire. In case of missing information during the first interview, the parents and teachers were contacted again a few days later to obtain the needed details. The parents and teachers' response rate was 99.64\%. Children diagnosed for ADHD and their parents were interviewed again for the symptoms of ADHD and impaired function. A proforma was specifically designed for this study which contains the child socio-demographic characteristics and background information such as age, sex, ethnicity, address, religion, school, class, the family structure, marital status of parents, parental educational attainment and occupation were documented in the proforma. The research was conducted by the researchers who had been trained in the use of DBDRS according to DSM-V criteria for ADHD. Socioeconomic status of the parents was classified with Oyedeji classification [54]. Highest social class was 1 and class $V$ the lowest. The socio economic class was re-stratified into upper (I \& II), middle (III) and lower (IV \& V) social groups [54].

Inclusion criteria: All apparently healthy school children aged 5-12 years and whose parents (guardians) gave consent while they assented to participate in the study.

Exclusion criteria: Pupils below the age of five years and above the age of twelve years were excluded. Children who declined participation in the study and children whose parent(s)/ guardian(s) refuse to give consent. Pupils who have spent less 6 months in the class as at the time of assessment and those on drugs such as neuro stimulant.

\section{Data Analysis}

All the data from DBDRS were entered into SPSS version 20. Descriptive statistics was used to describe socio demographic variables. Associations of proportions were tested using chi-squared test. A $p$-value of $<0.05$ was regarded as statistically significant. The internal consistencies of the instruments used (parent DBDRS and teachers' DBDRS) were evaluated with Cronbach's alpha, which were 0.94 and 0.92 respectively. Spearman correlation coefficients were calculated to evaluate informant agreement at the item level. 


\section{Result}

A total of 1,385 pupils were recruited for the study. The age range of the subjects was 5-12 years with the mean ( \pm SD) of $8.3( \pm 2.1)$ years. The result of the teachers' DBDRS showed male to female ratio of $1.03: 1.0$ and that of parents' DBDRS showed male to female ratio of 1.3:1.0. Socio Demographic Distribution of the Study Population is shown in table 1.

Table 1: Socio demographic distribution of the study population.

\begin{tabular}{l|l}
\hline \multicolumn{1}{c|}{ Characteristics } & \multicolumn{1}{c}{$\mathbf{N ~ ( \% )}$} \\
\hline Age & \\
\hline 5 to 7 & $535(38.6)$ \\
\hline 8 to 9 & $424(30.6)$ \\
\hline 10 to 12 & $426(30.8)$ \\
\hline Sex & $687(49.6)$ \\
\hline Male & $698(50.4)$ \\
\hline Female & \\
\hline Social class & $196(14.2)$ \\
\hline Upper class & $783(56.5)$ \\
\hline Middle class & $406(29.3)$ \\
\hline Lower class & \\
\hline Ethnicity & $1253(90.4)$ \\
\hline Yoruba & $127(9.2)$ \\
\hline Ibo & $5(0.4)$ \\
\hline Hausa & \\
\hline No of siblings & $1263(91.2)$ \\
\hline $0-3$ & $122(8.8)$ \\
\hline 4 and above & \\
\hline &
\end{tabular}

\section{Prevalence of ADHD among the pupils using teachers' DBDRS or parents' DBDRS and both}

One thousand three hundred and eighty five pupils were selected for the study, those diagnosed to have ADHD according to teacher's DBDRS was 140 (10.1\%) while 95 (6.9\%) were diagnosed by parents DBDRS. The difference in prevalence of ADHD using the teacher's DBDRS or parents DBDRS independently was statistically significant $\left.\chi^{2}=9.416, p=0.002\right)$. Sixty five $(4.7 \%)$ of the 1,385 pupils were identified by both the teachers and parents DBDRS to have ADHD as shown by area of overlap in the Venn diagram (Figure 1).

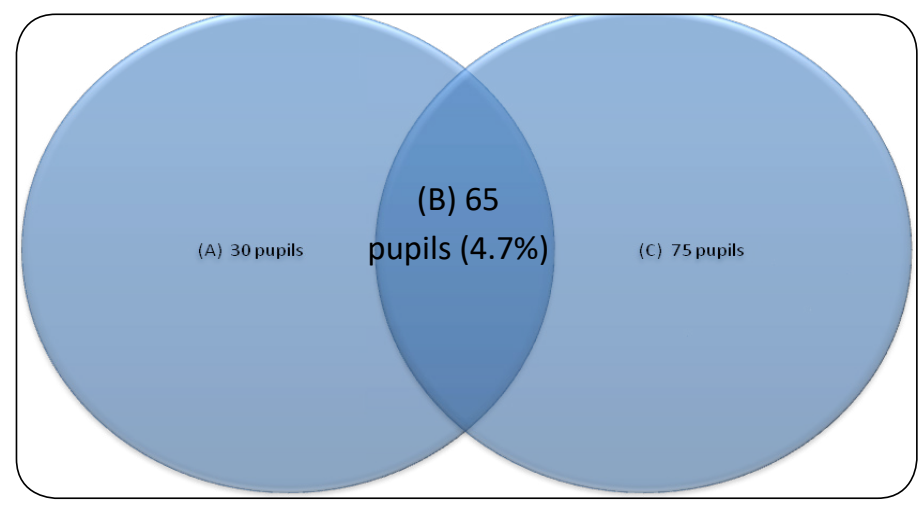

Parents' DBDRS Teachers' DBDRS

Figure 1: Prevalence of ADHD from Parents' and Teachers' DBDRS.

$A=30$ Pupils diagnose to have ADHD by parents DBDRS and not diagnosed to have ADHD by teachers DBDRS

$B=65$ Pupils (4.7\%) diagnosed by both the teachers and parents DBDRS to have ADHD (Agreement)

$C=75$ Pupils diagnosed to have ADHD by teachers' DBDRS and not diagnosed to have ADHD by parents' DBDRS

$A+B=95$ Pupils (6.9\%) diagnosed to have ADHD by parents DBDRS

$B+C=140$ Pupils (10.1\%) diagnosed to have ADHD by teachers' DBDRS

\section{Prevalence of ADHD subtypes based on Parents', Teachers 'and both Parents 'and Teachers' DBDRS}

Prevalence of ADHD Subtypes from the teachers', parents' and both teachers and parents DBDRS results was shown in figure 2 . The most prevalent subtype of ADHD was the predominantly inattentive subtype (ADHD-I), followed by the combined subtype (ADHD-C), while the least prevalent was hyperactivity/impulsive subtype (ADHD-HI). There was good agreement in the results of the teachers', parents' and both teachers and parents combined.

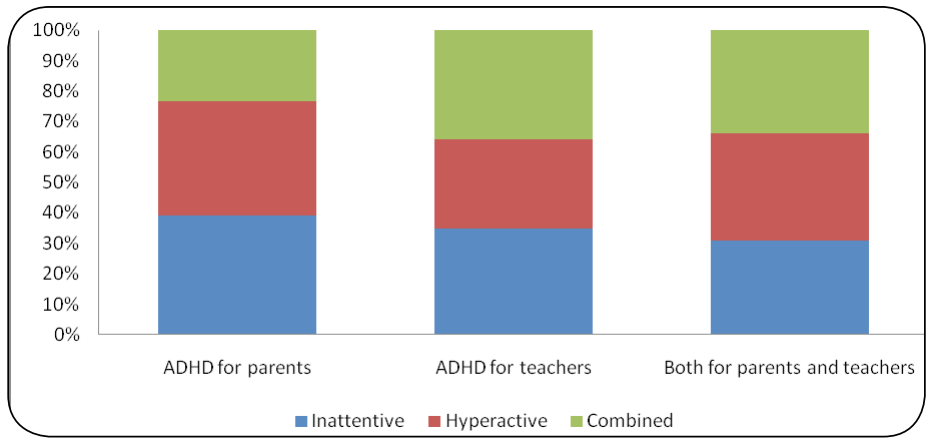

Figure 2: Prevalence of ADHD subtypes based on Parents', Teachers'and both Parents 'and Teachers' DBDRS. 
The association between prevalence of ADHD and gender

The association between prevalence of ADHD and gender shown in table 2 was not statistically significant in parents' DBDRS $\left(\left(c^{2}=1.562, p=0.126\right)\right.$ and teachers' DBDRS reports $\left(\left(c^{2}=0.770, p=0.790\right)\right.$.

\section{The association between prevalence of ADHD and the different age cohorts}

The association between prevalence of ADHD and the different age cohorts shown in table 3 was not statistically significant in parents' DBDRS $\left(\left(c^{2}=0.088, p=.0 .957\right)\right.$ and teachers' DBDRS $\left(\left(c^{2}=1.739 p=0.518\right)\right.$.

\section{Correlations between parents' and teachers rating on DBDRS}

Spearman Correlation was used to determine the levels of agreement between parents' and teachers' DBDRS reports of children's ADHD symptoms in table 4. Statistically significant positive correlations were found between parents' and teachers' ratings on both DBDRS: Inattention, $r=0.522, p<0.001$, hyperactivity, $r=$ $0.572, p<0.001$, Combined, $r=0.569, p<0.001$. There was a good correlation between parents' and teachers' DBDRS reports of children's with ADHD symptoms. $(r=$ $0.525, p<0.001)$

Table 2: The association between prevalence of ADHD and gender from Parents' DBDRS and, Teachers' DBDRS.

\begin{tabular}{l|l|l|l|r|l}
\hline \multirow{2}{*}{ DBDRS } & \multicolumn{2}{c|}{ Gender } & & & \\
\cline { 2 - 6 } & \multicolumn{1}{|c|}{ male(\%) } & female(\%) & Total N=1385 & c2 & P value \\
\hline Parent DBDRS & & & & 1.562 & 0.126 \\
\hline NO & $634(49.1)$ & $656(50.9)$ & $1290(93.1)$ & & \\
\hline YES & $53(55.8)$ & $42(44.2)$ & $95(6.9)$ & & \\
\hline Teacher DBDRS & & & & 0.77 & 0.79 \\
\hline NO & $616(49.5)$ & $629(51.5)$ & $1245(89.9)$ & & \\
\hline YES & $71(50.7)$ & $69(49.3)$ & $140(10.1)$ & & \\
\hline
\end{tabular}

DBDRS- Disruptive Behaviour Disorder Rating Scale.

Table 3: The association between Prevalence of ADHD and Age Group from Parent, Teacher and Both Parent and Teachers DBDRS.

\begin{tabular}{l|l|l|l|l|r|l}
\hline \multicolumn{1}{c|}{ DBDRS } & $\mathbf{5}$ to $\mathbf{7}$ & $\mathbf{8}$ to $\mathbf{9}$ & $\mathbf{1 0}$ to $\mathbf{1 2}$ & total $\mathbf{n = 1 3 8 5}$ & $\boldsymbol{\chi 2}$ & P value \\
\hline Parent DBDRS & 498 & 394 & 398 & 1290 & 0.088 & 0.957 \\
\hline NO & 37 & 30 & 28 & 95 & & \\
\hline YES & & & & & & \\
\hline Teacher DBDRS & & & & & 1.739 & 0.518 \\
\hline NO & 487 & 375 & 383 & 1245 & & \\
\hline YES & 48 & 49 & 43 & 140 & & \\
\hline
\end{tabular}

DBDRS- Disruptive Behaviour Disorder Rating Scale.

Table 4: Correlations between parents' and teachers rating on DBDRS.

\begin{tabular}{|c|c|c|c|c|c|c|}
\hline & 1 & 2 & 3 & 4 & 5 & 6 \\
\hline $\begin{array}{l}\text { Teacher } \\
\text { 1.Inattention } \\
\text { 2. Hyperactivity } \\
\text { 3. Combined }\end{array}$ & $\begin{array}{l}1 \\
0.555^{*} \\
0.670 *\end{array}$ & $\begin{array}{l}1 \\
0.846 *\end{array}$ & 1 & & & \\
\hline $\begin{array}{l}\text { Parents } \\
\text { 4. Inattention } \\
\text { 5. Hyperactivity } \\
\text { 6. Combined }\end{array}$ & $\begin{array}{l}0.522^{\star} \\
0.337^{\star} \\
0.408^{*}\end{array}$ & $\begin{array}{l}0.340 * \\
0.572 * \\
0.479 *\end{array}$ & $\begin{array}{l}0.414^{*} \\
0.485^{*} \\
0.569 *\end{array}$ & $\begin{array}{l}1 \\
0.505^{*} \\
0.644^{*}\end{array}$ & $\begin{array}{l}1 \\
0.799 *\end{array}$ & 1 \\
\hline
\end{tabular}

$$
\mathrm{P}<0.001 *
$$




\section{Discussion}

The present study found good level of agreement between parents' and teachers' reports of children's ADHD symptoms and its subtypes on the DBDRS. This finding was contrary to the observation by some authors who found low agreement between parents' and teachers' reports $[33,35,36,52]$. They used different sample size, tools and the age group contrary to this study. Cohen and colleagues compared parent and teacher ratings on the Conner's Rating scales and found moderate agreement between parents' and teachers' reports $[10,15]$. Though different instrument were used in the previous studies and were clinic based samples while in this study, DBDRS was used to screen the pupils and the samples were community based among the pupils who had not been earlier diagnosed to have ADHD. The reported good levels of agreement between parents and teachers on the DBDRS in this study could also be attributed to the fact that the parents and teachers of the pupils obviously appreciated this deviant behaviour in the children at home and in the school respectively. The sample population (1385) in this study was also higher than the previous studies with low to moderate agreement. Antrop et al. used DBDRS on 55 children in the age range of 6-12 years with clinically diagnosed ADHD and found low agreement between parents' and teachers' reports [35]. This could be as a result of knowledge bias of the diagnosis that parents had over the teacher in the study. Mitsis et al. assessed (74) seventy-four 7- to 11-year olds who had been referred to a programme for disruptive behaviours [33]. They found that parent reports of ADHD behaviour correlated higher with their own reports of their child's behaviour at home than with teacher reports of their child's behaviour at school [33]. Agreement between parents and teachers was found to be relatively poor, with virtually no agreement for individual ADHD subtypes in this study which is similar to study done by Antrop et al. [35]. Murray et al. compared agreement between parents and teachers reports for 452 children aged 3-5 years referred for an ADHD treatment and found low agreement in the study [37]. The children that participated in the Murray study with low agreement were aged 3-5 years while children that participated in this study with good agreement between parents and teachers reports were aged 5-12 years. The differences in age may also account for the variation in result. In previous studies using CBCL (Child Behavior Checklist)] and TRF (Teacher's Report Form) ratings, the average correlation between different types of informants (parent, teacher,) was 0.28 while correlation of 0.552 was found between parents and teachers reports using
DBDRS in this study [12-14]. Parents' and teachers' agreement on ADHD symptoms according to DBDRS were considerably good for hyperactivity, inattention and combined subtypes of ADHD in this study. Papageorgiou $V$ et al. found low to moderate agreement among 305 Greek children aged between 6-9 years [38] while good agreement was found in this study. The variation in result could be due to different sample size, tools and the age group considered. Parents are assumed to provide information about behaviours of the child at home, while teachers have information about the child's functioning at school and can compare a child's behaviour with that of other children in the same situation [32-35]. The good agreement of parent-teacher DBDRS implies that the attention deficit hyperactivity disorder symptoms were noted appreciably by both parents and teachers in different settings though with low bias.

\section{Acknowledgements}

I acknowledge the parents of the pupils, the head teachers, the teachers and the pupils in the schools used for this study for their cooperation. I also acknowledge the Local Inspector of Education who gave me the permission to use the schools.

\section{Limitations of the study}

Either of the available parents (the mother or father) was made to complete the parents' DBDRS, though, each of them may have their own bias regarding their children' behaviour. However more than $85 \%$ of the parents' DBDRS was completed by the mothers and the remaining by their fathers.

\section{Conflict of interest}

None to declare

\section{Source of funding}

The study was self-sponsored

\section{Ethical consideration}

Approval for the study was obtained from the Research and Ethics Committee of OAUTHC, Ile- Ife. Permission was also obtained from the Local Inspector of Education, head teachers of selected schools and class teachers from the selected classes.

\section{Informed consent}

Written informed consent was obtained from the parents or guardian of the children that took part in the study while assent of the pupils that participated was also obtained. 


\section{References}

1. American Psychiatric Association. Diagnostic and statistical manual of mental disorders. In: $4^{\text {th }}$ ed. Washington, DC; 2013. http://psychiatryonline.org/ doi/abs/10.1176/ajp.152.8.1228.

2. Polanczyk G, de Lima M, Horta B. The worldwide prevalence of ADHD: A systematic review and metaregression analysis. Am J Psychiatry. 2007;164(6):942-948. doi: https://doi.org/10.1176/ ajp.2007.164.6.942

3. Pastor P, Reuben C. Attention deficit disorder and learning disability: United States, 1997-98. Vital Health Stat 10. 2002;(206):1-12. https://www.ncbi. nlm.nih.gov/pubmed/15789507

4. Biederman J, Faraone S, Milberger S. A prospective 4-year follow-up study of attention-deficit hyperactivity and related disorders. Arch Gen Psychiatry. 1996;53(6):437-446. doi: https://doi. org/10.1001/archpsyc.1996.01830050073012

5. Mannuzza S, Klein RG, Moulton JL. Persistence of attention-deficit/hyperactivity disorder into adulthood: What have we learned from the prospective follow-up studies? J Atten Disord. 2003;7(2):93-100. doi: https://doi.org/10.1177/108705470300700203

6. Americanacademy of paediatrics committee on quality improvement. Subcommittee on attention-deficit/ hyperactivity disorder: clinical practice guideline: diagnosis and evaluation of the child with attention deficit/hyperactivity. Paediatrics. 2000;105:1158. doi: https://doi.org/10.1542/peds.105.5.1158

7. Barkley RA. Attention deficit hyperactivity disorder: a handbook for diagnosis and treatment. $3^{\text {rd }}$ ed. New York: Guilford Publications; 2005. http://www. myilibrary.com?id=112393.

8. Mayes SD, Calhoun SL, Crowell EW. Learning disabilities and ADHD: overlapping spectrum disorders. J Learn Disabil. 2000;33(5):417-424. doi: https://doi.org/10.1177/002221940003300502

9. Achembach TM, Rescorla LA. Manual for the ASEBA school-age forms \& profiles. Burlington, VT: University of Vermont. Research Centre for Children, Youth \& Families. 2001;4.

10. Sullivan JR, Swerdlik ME, Swerdlik P, et al. Psychological processing checklist. North Tonawanda, NY: MultiHealth Systems. J Psychoeduc Assess. 2007;25(2):190198. doi: https://doi.org/10.1177/0734282906295403

11. Reynolds CR, Kamphaus RW. Behavior assessment system for children. $2^{\text {nd }}$ ed. Bloomington: $M N$ :
Pearson Assessments; 2004.

12. Achenbach TM, McConaughy SH, Howell CT. Child/adolescent behavioral and emotional problems: Implications of cross-informant correlations for situational specificity. Psychological Bulletin. 1987;101(2):213-232. doi: https://doi. org/10.1037/0033-2909.101.2.213

13. Achenbach TM, Dumenci L, Rescorla LA. DSMoriented and empirically based approaches to constructing scales from the same item pools. J Clin Child Adolesc Psychol. 2003;32(3):328-340. doi: https://doi.org/10.1207/S15374424JCCP3203_02

14. Achenbach TM, Rescorla L. Manual for the ASEBA school-age forms and profiles. Burlington, VT: ASEBA; 2001.

15. Cohen M, Riccio C, Gonzalez J. Methodological differences in the diagnosis of attention-deficit hyperactivity disorder: Impact on prevalence. J Emot Behav Disord. 1994;2(1):31-38. doi: https://doi. org/10.1177/106342669400200104

16. Reid R, Maag JW. How many fidgets in a pretty much: A critique of behavior rating scales for identifying students with ADHD.JSch Psychol. 1994;32(4):339-354. doi: https://doi.org/10.1016/0022-4405(94)90032-9

17. Rohde LA. Is there a need to reformulate attention deficit hyperactivity disorder criteria in future nosologic classifications? Child Adolesc Psychiatr Clin N Am. 2008;17(2):405-420. doi: https://doi. org/10.1016/j.chc.2007.11.007

18. Pliszka S. Practice parameter for the assessment and treatment of children and adolescents with attentiondeficit/hyperactivity disorder. J Am Acad Child Adolesc Psychiatry. 2007;46(7):894-921. doi: https:// doi.org/10.1097/chi.0b013e318054e724

19. Nakamura BJ, Ebesutani C, Bernstein A, Chorpita BF. A psychometric analysis of the Child Behavior Checklists DSM-oriented scales. J Psychopathol Behav Assess. 2009;31(3):178-189. doi: https://doi. org/10.1007/s10862-008-9119-8

20. Brown RT, Freeman WS, Perrin JM, et al. Prevalence and assessment of attention-deficit/hyperactivity disorder in primary care settings. Pediatrics. 2001;107(3):e43-e43. doi: https://doi.org/10.1542/ peds.107.3.e43

21. Pelham WE, Gnagy EM, Greenslade KE, Milich R. Teacher ratings of DSM-III-R symptoms for the disruptive behavior disorders. J Am Acad Child Adolesc Psychiatry. 1992;31(2):210-218. doi: https:// doi.org/10.1097/00004583-199203000-00006 
22. Meyer A. Attention-deficit/hyperactivity disorder among north sotho speaking primary school children in South Africa: prevalence and sex ratios. J Psychol Afr. 1998;8:186-195. https://www. researchgate.net/publication/299368196_AttentionDeficitHyperactivity_Disorder_among_North_Sotho_ speaking_primary_school_children_in_South_Africa_ Prevalence_and_sex_ratios

23. Kashala E, Elgen I, Sommerfelt K, Tylleskar T. Attention deficit and hyperactivity disorder among school children in Kinshasa, Democratic Republic of Congo. Afr Health Sci. 2005;14(5):172-181. doi: https://doi. org/10.1007/s00787-005-0446-y

24. Ibadin M, Ambuabunos E, Ofovwe E. Community survey of attention-deficit / hyperactivity disorder among primary school pupils in Benin City, Nigeria. Ann Afr Med. 2011;10(2):91-96. doi: https://doi. org/10.4103/1596-3519.82065

25. Zeiner P. Parent-reported symptoms of hyperactivity and attention deficits predict teacher-reported symptoms. Acta Paediatrica. 1997;86(2):178-182. doi: https://doi.org/10.1111/j.1651-2227.1997.tb08863.x

26. Amador-Campos JA, Forns-Santacana $M$, GuàrdiaOlmos J, Peró-Cebollero M. DSM-IV attention deficit hyperactivity disorder symptoms: Agreement between informants in prevalence and factor structure at different ages. J Psycho pathol Behav Assess.2006;28(1):23-32. doi: https://doi.org/10.1007/ s10862-006-4538-x

27. Dinnebeil LA, Rule S. Congruence between parents' and professionals' judgments about the development of young children with disabilities. Top. Early Child. Special Educ. 1994;14(1):1-25. doi: https://doi. org/10.1177/027112149401400105

28. Hartman CA, Rhee SH, Willcutt EG, Pennington BF. Pennington BF. Modeling rater disagreement for ADHD: Are parents or teachers biased? J Abnorm Child Psychol. 2007;35(4):536-542. doi: https://doi. org/10.1007/s10802-007-9110-y

29. Stanger C, Lewis M. Agreement among parents, teachers, and children on internalizing and externalizing behavior problems. J Clin Child Adolesc Psychol. 1993;22(1):107-116. doi: https://doi. org/10.1207/s15374424jccp2201_11

30. Sullivan JR, Riccio CA. Diagnostic group differences in parent and teacher ratings on the BRIEF and Conners' Scales.J Atten Disord. 2007;11(3):398-406. doi: https:// doi.org/10.1177/1087054707299399

31. Tassé MJ, Lecavalier L. Comparing parent and teacher ratings of social competence and problem behaviors. Am J Ment Retard. 2000;105(4):252-259. doi: https:// doi.org/10.1352/0895-8017(2000)105<0252:CPATRO $>2.0 . \mathrm{CO} ; 2$

32. Power TJ, Andrews TJ, Eiraldi RB, et al. Evaluating attention deficit hyperactivity disorder using multiple informants: The incremental utility of combining teacher with parent reports. Psychol Assess. 1998;10(3):250-260. doi: https://doi. org/10.1037/1040-3590.10.3.250

33. Mitsis EM, McKay KE, Schulz KP, Newcorn JH, Halperin JM. Parent-teacher concordance for DSM-IV attention-deficit/hyperactivity disorder in a clinic-referred sample. J Am Acad Child Adolesc Psychiatry. 2000;39(3):308-313. doi: https://doi. org/10.1097/00004583-200003000-00012

34. Wolraich ML, Lambert EW, Bickman L, Simmons T, Doffing MA, Worley KA. Assessing the impact of parent and teacher agreement on diagnosing attention-deficit hyperactivity disorder. J Dev Behav Pediatr. 2004;25(1):41-47. doi: https://doi. org/10.1097/00004703-200402000-00007

35. Antrop I, Roeyers H, Oosterlaan J, Van Oost P. Agreement between parent and teacher ratings of disruptive behavior disorders in children with clinically diagnosed ADHD. J Psychopathol Behav Assess. 2002;24(1):67-73. doi: https://doi. org/10.1023/A:1014057325752

36. Mandal RL, Olmi DJ, Wilczynski SM. Concordance between multiple informants in the diagnosis of attention-deficit/hyperactivity disorder. J Atten Disord. 1999;3(2):97-103. doi: https://doi. org/10.1177/108705479900300204

37. Murray DW, Kollins SH, Hardy KK, et al. Parent versus teacher ratings of attention-deficit/hyperactivity disorder symptoms in the Preschoolers with attentiondeficit/hyperactivity disorder treatment study (PATS). J Child Adolesc Psychopharmacol. 2007;17(5):605620. doi: https://doi.org/10.1089/cap.2007.0060

38. Papageorgiou V, Kalyva E, Dafoulis V, Vostanis P. Differences in parents' and teachers' ratings of ADHD symptoms and other mental health problems. Eur J Psychiat. 2008;22(4):200-210. doi: https://doi. org/10.4321/S0213-61632008000400003

39. Biederman J, Keenan K, Faraone SV. Parent-based diagnosis of attention deficit disorder predicts a diagnosis based on a teacher report. J Am Acad Child Adolesc Psychiatry. 1990;29(5):698-701. doi: https:// doi.org/10.1097/00004583-199009000-00004 
40. Christensen A, Margolin G, Sullaway M. Interparental agreement on child behavior problems. Psychol Assess. 1992;4(4):419-425. doi: https://doi. org/10.1037/1040-3590.4.4.419

41. Faraone SV, Biederman J, Zimmerman B. Correspondence of parent and teacher reports in medication trials. Eur Child Adolesc Psychiatry. 2005;14(1):20-27. doi: https://doi.org/10.1007/ s00787-005-0415-5

42. Kraemer HC, Measelle JR, Ablow JC, Essex MJ, Boyce WT, Kupfer DJ. A new approach to integrating data from multiple informants in psychiatric assessment and research: Mixing and matching contexts and perspectives. Am J Psychiatry. 2003;160(9):1566-1577. doi: https://doi.org/10.1176/appi.ajp.160.9.1566

43. Landis JR, Koch GG. The measurement of observer agreement for categorical data. Biometrics. 1977;33(1):159-174. doi: https://doi. org/10.2307/2529310

44. Langberg JM, Epstein JN, Simon JO, et al. Parent agreement on ratings of children's attention deficit/ hyperactivity disorder and broadband externalizing behaviors. J Emot Behav Disord. 2010;18(1):41-50. doi: https://doi.org/10.1177/1063426608330792

45. Loeber R, Green S, Lahey B. Mental health professionals' perception of the utility of children, mothers, and teachers as informants on childhood psychopathology. J Clin Child Adolesc Psychol. 1990;19(2):136-143. doi: https://doi.org/10.1207/ s15374424jccp1902_5

46. Offord DR, Boyle $M H$, Racine $\mathrm{Y}$, et al. Integrating assessment data from multiple informants. J Am Acad Child Adolesc Psychiatry. 1996;35(8):1078-1085. doi: https://doi.org/10.1097/00004583-199608000-00019

47. Phares V. Accuracy of informants: do parents think that mother knows best? J Abnorm Child Psychol.
1997;25(2):165-171. https://www.ncbi.nlm.nih.gov/ pubmed/9109033

48. Power TJ, Andrews TJ, Eiraldi RB, et al. Evaluating attention deficit hyperactivity disorder using multiple informants: The incremental utility of combining teacher with parent reports. Psychol Assess. 1998;10(3):250-260. doi: https://doi. org/10.1037/1040-3590.10.3.250

49. Tripp G, Schaughency EA, Clarke B. Parent and teacher rating scales in the evaluation of attention-deficit hyperactivity disorder: Contribution to diagnosis and differential diagnosis in clinically referred children. J Dev Behav Pediatr. 2006;27(3):209-218. doi: https:// doi.org/10.1097/00004703-200606000-00006

50. Youngstrom EA, Findling RL, Calabrese JR. Who are the comorbid adolescents? Agreement between psychiatric diagnosis, youth, parent, and teacher report. J Abnorm Child Psychol. 2003;31(3):231-245. doi: https://doi.org/10.1023/A:1023244512119

51. Youngstrom E, Loeber R, Stouthamer-Loeber $M$. Patterns and correlates of agreement between parent, teacher, and male adolescent ratings of externalizing and internalizing problems. J Consult Clin Psychol. 2000;68(6):1038-1050. doi: https://doi. org/10.1037/0022-006X.68.6.1038

52. van der Oord S, Prins PJM, Oosterlaan J, Emmelkamp PMG. The association between parenting stress, depressed mood and informant agreement in ADHD and ODD. Behav Res Ther. 2006;44(11):1585-1595. doi: https://doi.org/10.1016/j.brat.2005.11.011

53. National Population Commission. Population and Housing Census of the Federal Republic of Nigeria. Vol 1. Osun State; 2006.

54. Oyedeji G. Socio-economic and cultural background of hospitalized children in Ilesa, Nig. J Paediatr.1985;12:111-117. reproduction in any medium, provided the original work is properly cited. 